\title{
Can external defibrillation terminate electrical storm in patients with cardiac resynchronization therapy defibrillator? A case report
}

\author{
Xiuyan $\mathrm{Lu}^{1 *}$, Rong $\mathrm{Lv}^{2}$, Tao Liang ${ }^{1}$ and Ying $\mathrm{Zhai}^{3}$ \\ ${ }^{1}$ School of Nursing, Peking Union Medical College, Beijing, China \\ ${ }^{2}$ Fuwai Hospital of the Chinese Academy of Medical Sciences, Department of cardiovascular medicine, Beijing, China \\ ${ }^{3}$ General Hospital of Rocket Army, Beijing, China
}

\begin{abstract}
Implantable cardioverter-defibrillator has become the main therapeutic tool for use in patients with life-threatening ventricular arrhythmias to prevent sudden cardiac death. However, patients with implantable cardioverter-defibrillators can develop the complication of electrical storm. Electrical storm is defined by 3 or more sustained episodes of ventricular tachycardia, ventricular fibrillation, or appropriate shocks from an implantable cardioverter-defibrillator within 24 hours. Because the ICD is becoming more prevalent, the complication of electrical storm has received greater attention in clinical practice.
\end{abstract}

In this case study, the authors report positive outcome of using external defibrillator to treat electrical storm for a 75-year-old male with cardiac resynchronization therapy-defibrillator (CRT-D).

\section{Background}

Heart failure (HF) is end stage of various organic heart diseases, and irreversible damage of myocardium seriously affects cardiac function. The ventricular synchronous pacing is among the most important methods to treat this condition. Among the ventricular synchronous pacing therapies, cardiac resynchronization therapy (CRT) can regulate ventricular function and improve the clinical status of patients. Also, patients with poor left ventricular ejection fraction (LVEF) have higher incidence of sudden cardiac death associated with ventricular arrhythmias, and the Implantable cardioverter-defibrillator (ICD) can prevent cardiac sudden death. The implantation of CRT-D that combines ICD function with CRT has become an effective therapy to improve the prognosis of heart failure patients. This therapy has been developing very rapidly in recent years [1] and has become class I indication for treating patients with LEVF $\leq 35 \%$. However, patients with implantable cardioverter-defibrillators can develop the complication of electrical storm [2]. Because the complication of electrical storm is life threatening emergency, and management of this complication has received greater attention in clinical practice.

\section{Case presentation}

A 75-year-old male was admitted to the hospital with coronary atherosclerotic heart disease, cardiac enlargement, premature ventricular beats, heart failure, cardiac function IV (NYHA classification), hypertension class III, hyperlipidemia and constipation. He had a history of smoking for 40 years and has quit for past 20, hyperlipidemia for 15 years, hypertension over 20 years with highest reading of $180 / 100 \mathrm{mmHg}$. He has no history of alcoholism or drug abuse. During hospitalization, the cardio echogram indicated: LVEF16\%, LA 46mm, LV 76mm, and the left ventricle was significantly enlarged. Continuous monitoring showed premature ventricular extra systole contingently and brief paroxysmal ventricular tachycardia.
CRT-D was implanted for the arrhythmia on June 15, 2017, the 7th day after admission. On the 8th day, while the patient was defecating, he reported rapid heartbeat and blindness, and then he became unconscious. The monitor indicated he was experiencing electric storm, although the cardiac resynchronization therapy-defibrillator(CRT-D) had been implanted. After 11 shocks of the CRT-D, the patient still had malignant ventricular arrhythmia (Table 1, the CRT - D rescue report). The rescue team-initiated CPR, external defibrillations, and administered dopamine, adrenalin, amiodarone, rocuronium bromide and sodium bicarbonate. After 5 shocks with the automated external defibrillator (AED), the patient returned to normal sinus rhythm. Meanwhile, other team members assessed for possible primary causes for the electrical storm $[3,4]$.

\section{Discussion}

After discussing this experience, the team members concluded the following: First, we must consider using external defibrillation in time, which has higher defibrillation energy, to terminate ventricular tachycardia and/or ventricular fibrillation when a patient's implantable cardioverter-defibrillator fails to control these malignant arrhythmias [5]. Second, nurses should constantly monitor possible primary causes underlying malignant arrhythmias. Possible causes include hypovolemia, hypoxia, acidosis, hyper-/hypokalemia, cardiac tamponade, tension pneumothorax, cardiac and pulmonary thrombosis (AHA, 2015)

Correspondence to: Tao Liang, Doctor of Nursing of Cardiovascular Disease. School of Nursing, Peking Union Medical College, Beijing, China

Key words: external defibrillation, cardiac resynchronization therapy-defibrillator, electrical storm

Received: February 20, 2018; Accepted: March 10, 2018; Published: March 12, 2018 
Table 1. Record of CRT-D defibrillation in rescue process

\begin{tabular}{|c|c|c|c|c|c|c|}
\hline Type & $\begin{array}{l}\text { ATP } \\
\text { seq }\end{array}$ & Shocks & Success & $\begin{array}{c}\text { Time } \\
\text { hh:mm }\end{array}$ & $\begin{array}{c}\text { Duration } \\
\text { Hh:MM: SS }\end{array}$ & $\begin{array}{c}\text { Avg bpm } \\
\text { A/V }\end{array}$ \\
\hline FVT & 4 & $35 \mathrm{~J}, 35 \mathrm{~J}$ & YES & $11: 48$ & $0: 01: 14$ & $158 / 162$ \\
\hline FVT & 2 & & NO & $11: 50$ & 0:01:03 & $-/ 182$ \\
\hline High rate-NS & & & & $11: 51$ & 0:00:02 & $-/ 333$ \\
\hline FVT & 1 & & YES & $11: 52$ & 0:00:54 & $-/ 167$ \\
\hline FVT & 4 & $15 \mathrm{~J}, 35 \mathrm{~J}$ & YES & $11: 53$ & 0:01:17 & $-/ 194$ \\
\hline FVT & 1 & $35 \mathrm{~J}, 35 \mathrm{~J}$ & YES & $11: 55$ & 0:00:42 & $-/ 200$ \\
\hline VF & 1 & & YES & $11: 58$ & $0: 01: 24$ & -250 \\
\hline \multicolumn{7}{|l|}{$\ldots \ldots \ldots$} \\
\hline FVT & 2 & & YES & $12: 42$ & 0:00:14 & $-/ 200$ \\
\hline FVT & 2 & & YES & $12: 43$ & 0:00:16 & $-/ 194$ \\
\hline FVT & 3 & & YES & $12: 45$ & 0:00:28 & $-/ 150$ \\
\hline FVT & 1 & & YES & $12: 46$ & 0:00:10 & $-/ 200$ \\
\hline ........... & & & & & & \\
\hline
\end{tabular}

Note. $\mathrm{FVT}=$ fast ventricular tachycardia, $\mathrm{VF}=$ ventricular fibrillation, $\mathrm{ATP}=$ ant tachycardia pacing

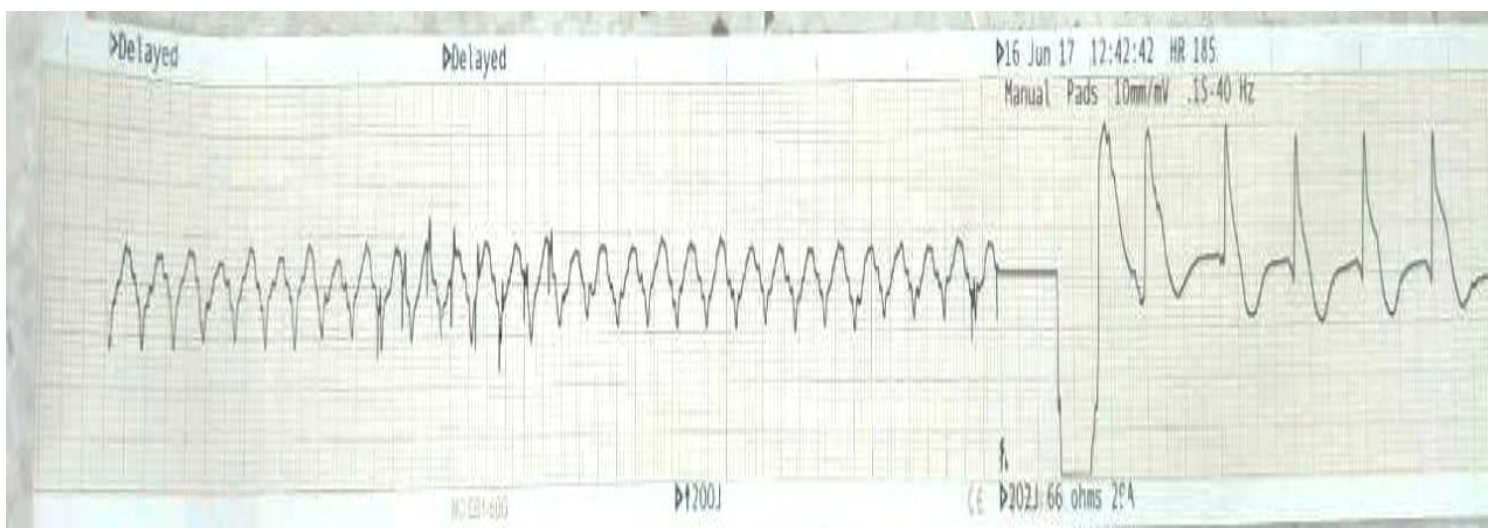

Figure 1. The electrocardiogram after patients were treated with AED

Third, the team suspects that the patient's forced defecation may have been one of contributing factors to the development of the electrical storm This suggests that interventions for prevention of constipation should be implemented from the first day of admission.

Because of this experience, the team members wondered why the ATP did not initiate shocks as soon as the malignant ventricular arrhythmias occurred? After consulting the literature, we learned that the following factors may be related to this issue: 1) The perimeter of tachycardia is the most critical factor; it becomes more difficult for ATP to stop VT when its perimeter becomes longer. 2) The size of excitable gap is related to the VT perimeter and placement of pacing electrodes. When the perimeter is shorter, and the placement is nearer, the excitable gap becomes smaller. 3) The third factor is the distance between the position of the pacing electrode and the exit distance of the exhumation excitation. The farther the distance, the more difficult it is to terminate the malignant ventricular arrhythmias. 4) The forth factor is the length of the irritation part of the pacing and the exportation of the exhumation ring [6]. In addition, we also wondered why CRT-D does not defibrillate immediately when patients have ventricular arrhythmias? To rule out the problem that may be caused CRT-D itself, we must first satisfy the following two basic conditions for detection of ventricular arrhythmias. First, the RR interval should conform to the prescribed range of ventricular tachycardia, and then the arrhythmia that meets this range will continue to exceed the prescribed time (Figure 1).

\section{Conclusion}

Finally, we must consider whether the use of external defibrillation affect the function of the CRT-D. If yes, what is the effect and how could it be avoided? These questions have yet to be further studied.

\section{References}

1. Hsu JC, Solomon SD, Bourgoun M, et al. (2012) Predictors of super-response to cardiac resynchronization therapy and associated improvement in clinical outcome: the MADIT-CRT (multicenter automatic defibrillator implantation trial with cardiac resynchronization therapy) study. J Am Coll Cardiol 59: 2366-2373. [Crossref]

2. Nakou ES (2016) 213 ESC Guidelines on cardiac pacing and cardiac resynchronization therapy. Eur Heart J 34: 2281-2329.

3. Miller JD, Youssef O, Berger RD (2015) The implantable cardioverter-defibrillator: An update. Trends Cardiovasc Med 25: 606-611. [Crossref]

4. Cabanelas N, Oliveira M, Nogueira da SM, et al. (2014) The proarrhythmic effect of cardiac resynchronization therapy: an issue that should be borne in mind. Rev Port Cardiol 33: 309. [Crossref]

5. Pisano P Jr, Mazzola JG, Tassiopoulos A, et al. (2016) Electrosurgery and ultrasonics on patients with implantable cardiac devices: Evidence of side effects in the dental practice. Quintessence Int 47: 151-160. [Crossref]

6. Josephson ME (2002) Clinical Cardiac Electrophysiology: Techniques and Interpretations. $3^{\text {rd }}$ edition. Lippincott Williams \& Wilkins.

Copyright: (C2018 Xiuyan Lu. This is an open-access article distributed under the terms of the Creative Commons Attribution License, which permits unrestricted use, distribution, and reproduction in any medium, provided the original author and source are credited. 